\title{
Inhibition of Pectin Methyl Esterase Activity By Green Tea Catechins
}

\section{Citation}

Lewis, Kristin C., Tzvia Selzer, Chen Shahar, Yael Udi, Dmitry Tworowski, Irit Sagi. 2008. Inhibition of pectin methyl esterase activity by green tea catechins. Phytochemistry 69: 25862592.

\section{Published Version}

http://dx.doi.org/10.1016/j.phytochem.2008.08.012

\section{Permanent link}

http://nrs.harvard.edu/urn-3:HUL.InstRepos:2338528

\section{Terms of Use}

This article was downloaded from Harvard University's DASH repository, and is made available under the terms and conditions applicable to Other Posted Material, as set forth at http:// nrs.harvard.edu/urn-3:HUL.InstRepos:dash.current.terms-of-use\#LAA

\section{Share Your Story}

The Harvard community has made this article openly available.

Please share how this access benefits you. Submit a story.

\section{Accessibility}


Kristin C. Lewis, Tzvia Selzer, Chen Shahar, Yael Udi, Dmitry Tworowski, Irit Sagi. 2008. Inhibition of pectin methyl esterase activity by green tea catechins. Phytochemistry 69: 25862592. doi:10.1016/j.phytochem.

\section{Graphical Abstract}

Pectin methyl esterases and their endogenous inhibitors are involved in many processes in plant physiology. Exogenous inhibitors of PME can be used to further our understanding of these processes. We identify the green tea catechin epigallocatechin gallate as a natural inhibitor of pectin methyl esterases from multiple taxa.
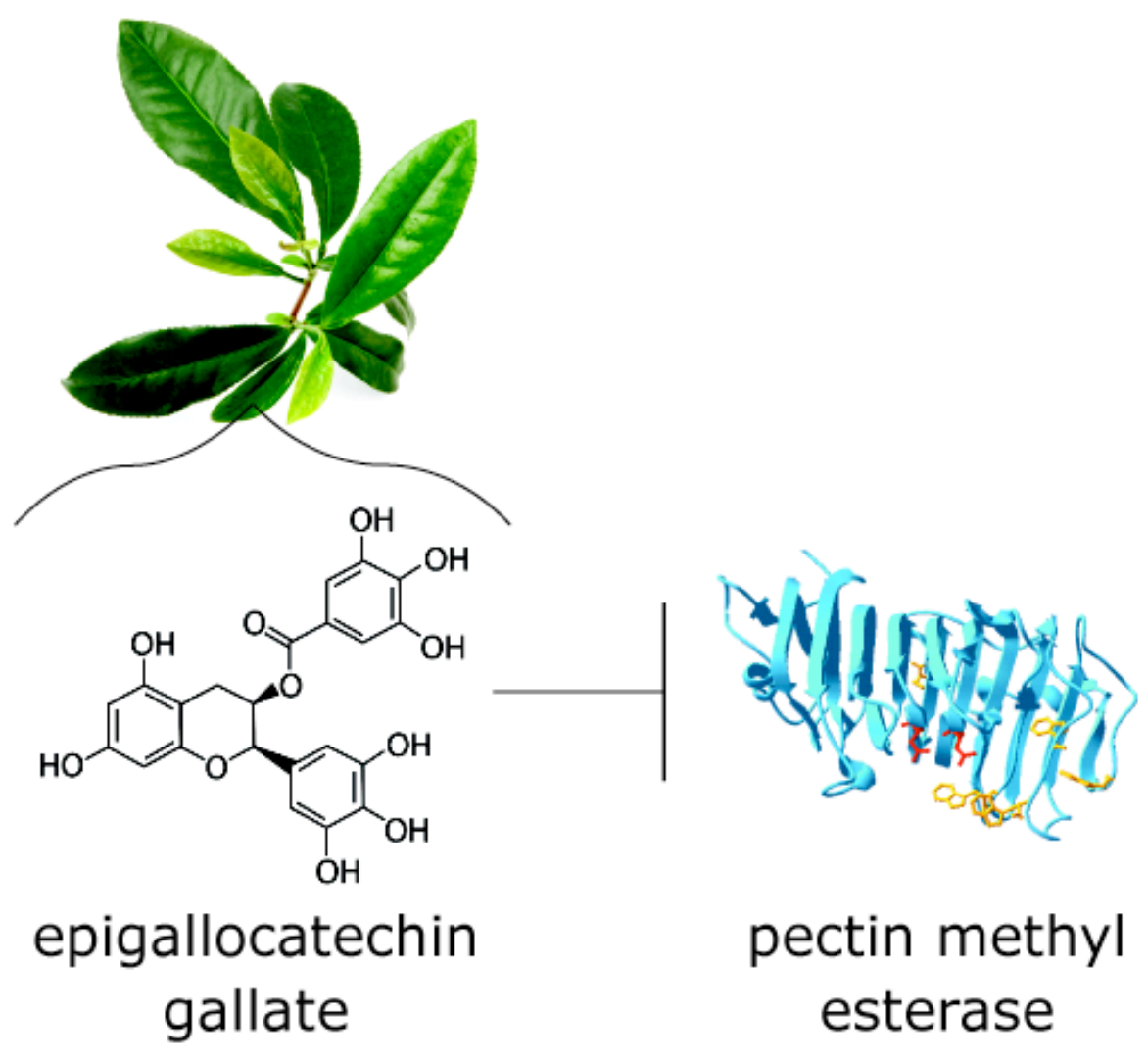


\section{INHIBITION OF PECTIN METHYL ESTERASE ACTIVITY BY GREEN TEA CATECHINS.}

\section{Kristin C. Lewis*a ${ }^{*}$ Tzvia Selzer $^{\text {b }}$, Chen Shahar ${ }^{\text {b }}$, Yael Udi ${ }^{b}$, Dmitry Tworowski ${ }^{b}$, Irit Sagi*b}

${ }^{a}$ Rowland Institute at Harvard, 100 Edwin H. Land Boulevard, Cambridge, MA 02141.

${ }^{\mathrm{b}}$ Weizmann Institute of Science, Department of Structural Biology, Rehovot 76100, Israel Corresponding authors: Kristin Lewis, Rowland Institute at Harvard, 100 Edwin H. Land Boulevard, Cambridge, MA 02141. Fax: 617-497-4627; E-mail: lewis@rowland.harvard.edu Irit Sagi, Weizmann Institute of Science, Department of Structural Biology, Rehovot 76100, Israel. Tel: 972-8-9342130; Email: irit.sagi@weizmann.ac.il 


\begin{abstract}
Pectin methyl esterases (PMEs) and their endogenous inhibitors are involved in the regulation of many processes in plant physiology, ranging from tissue growth and fruit ripening to parasitic plant haustorial formation and host invasion. Thus, control of PME activity is critical for enhancing our understanding of plant physiological processes and regulation. Here we report on the identification of epigallocatechin gallate (EGCG), a green tea component, as a natural inhibitor for pectin methyl esterases. In a gel assay for PME activity, EGCG blocked esterase activity of pure PME as well as PME extracts from citrus and from parasitic plants.

Fluorometric tests were used to determine the IC50 for a synthetic substrate. Molecular docking analysis of PME and EGCG suggests close interaction of EGCG with the catalytic cleft of PME . Inhibition of PME by the green tea compound, EGCG, provides means to study the diverse roles of PMEs in cell wall metabolism and plant development. In addition, this study introduces the use of EGCG as natural product to be used in the food industry and agriculture.
\end{abstract}

Keywords: Camellia sinensis, Theaceae, green tea, Cuscuta pentagona, Cuscutaceae, dodder, Castilleja indivisa, Orobanchaceae, entireleaf Indian paintbrush, cell wall degrading enzymes, inhibition, parasitism, pectin methyl esterase, catechins, epigallocatechin gallate.

\title{
Introduction
}

Pectin methyl esterase (PME), which modifies esterified homogalacturonan components of pectin found in plant cell walls, is a critical enzyme for tissue remodeling, growth, and fruit maturation, among other processes (Brummell, 2006; Derbyshire et al., 2007; Jarvis et al., 2003). Homogalacturonan, one of the two pectin polysaccharide backbones, is highly methyl-esterified when exported into cell walls and is subsequently de-esterified by the action of PME and other pectic enzymes (Willats et al., 2001; Zhang and Staehelin, 1992). The control of methyl esterification levels by PMEs has been recently reported to have a direct effect on the regulation of a wide range of processes in plant physiology, including cell-to-cell adhesion and separation (e.g., abscission) (Jarvis et al., 2003; Willats et al., 2001), cellular elongation, germination and 
seedling growth, (Derbyshire et al., 2007), and fruit ripening (reviewed in Brummell, 2006; e.g., Koch and Nevins, 1989). Some PMEs are ubiquitously expressed, whereas others are expressed in specific tissue regions (Christensen et al., 1998; Micheli et al., 2000; Nielsen and Christensen, 2002) or during specific life stages or events, such as pollination (Jiang et al., 2005; Li et al., 1994), or parasitic plant haustorial formation (Nagar et al., 1984). The data suggest that PMEs are encoded by a family of genes (Micheli et al., 1998) that are differentially regulated by cell type in response to specific developmental or environmental scenarios (Derbyshire et al., 2007; Raiola et al., 2004; Wolf et al., 2003). In addition, enzymatic activity is regulated by direct interaction with endogenous inhibitors in plant tissue (Giovane et al., 2004; Raiola et al., 2004; Wolf et al., 2003). These protein inhibitors specifically interact with the enzyme active site region and hamper substrate access. Regulation of PME activity by exogenous application of inhibitors may offer a way to investigate the roles of PME in cell wall modification during a variety of plant life stages and tissues.

Regulation of PME activity by endogenous protein inhibitors may be altered during tissue invasion processes that require cell wall degradation, for example, during host invasion by plant parasites (Ben-Hod et al., 1993; Losner-Goshen et al., 1998; Nagar et al., 1984; Vaughn, 2003; Veronesi et al., 2005). Plants resistant to invasion appear to exhibit strong inhibition of cell wall degrading enzymes at tissue surfaces (Singh and Singh, 1997). Therefore, exogenous blocking of PME enzymatic activity in parasitic plants during the invasion process may be used to prevent parasitism.

However, the use of proteinaceous inhibitors is complex and hence not trivial. Small molecule inhibitors would be more tractable as applied enzyme inhibitors. Several proteinaceous inhibitors of pectin methyl esterase (termed PMEIs) have been identified (D'Avino et al., 2003; Giovane et al., 2004; Juge, 2006; Raiola et al., 2004; Wolf et al., 2003). However, to our knowledge, no small molecules have been implicated in inhibition of PME to date. Yet plants are adept at producing highly bioactive small molecules, and these may offer a less metabolically costly way to inhibit PME. Small molecules may also be more practical for exogenous 
application due to their long shelf life and stability compared to protein inhibitors. Furthermore, the exogenous application of small molecule inhibitors offers a method for fine control of enzymatic activity during isolated life stages and tissues. Previous work using antisense technology to inhibit PME (e.g., Pilling et al., 2004) has shown systemic effects of PME inhibition, but are difficult to confine to particular plant parts or life stages, nor are they tractable for field experiments on non-model systems. Therefore, we endeavored to identify appropriate small molecules that have shown efficacy as enzymatic inhibitors, as a starting point for identifying candidate PME inhibitors. By analogy to mammalian tissue-degrading enzymes, we identified green tea (Camellia sinensis) catechins as potential inhibitors of PME due to their inhibition of carboxypeptidases (which also have esterase activity) during tissue remodeling in mammalian systems (Holmquist and Vallee, 1976).

Our research has identified a novel inhibitor for pectin methyl esterase activity. We have found that green tea catechin extract (called Polyphenon 60, or PP60) inhibits citrus and tomato PME activity in vitro, and inhibits parasitic plant PME extracts from both dodder (Cuscuta pentagona) and Indian paintbrush (Castilleja indivisa), representatives of two large families of parasitic plants, the Cuscutaceae and Orobanchaceae. In addition, we found that epigallocatechin gallate (EGCG) and gallocatechin gallate (GCG), the catechins containing active gallate esters, were the most active in PME inhibition. Molecular docking analyses and fluorometric measurements indicate the close interaction of EGCG with the active site of PME.

\section{Results and Discussion}

\section{Green tea catechin extract inhibits PME in a concentration dependent manner.}

Enzymatic activity of solutions of commercially available citrus PME and PME plus PP60 was tested using ruthenium red staining of pectin-infused plates of agarose medium (Downie et al., 1998). A serial dilution of PME solution was incubated in agarose plates with and without PP60. The one-way analysis of variance (ANOVA) showed a significant effect of catechin addition on staining diameter $\left(\mathrm{F}_{11,48}=1024.2, \mathrm{p}<0.0001\right)$. Ruthenium red stain of de-esterified pectin was 
observed around each well that contained control PME samples, with diameter dependent upon PME concentration (Figure 1a). No de-esterification was observed around any of the wells containing PP60, indicating loss of enzymatic function with addition of PP60.

A Tukey's post-hoc test comparing diameters among PME solutions showed no difference between $1 \mathrm{mg} / \mathrm{mL}$ PME and $0.75 \mathrm{mg} / \mathrm{mL}$ PME, but significant differences among all other PME treatments. All solutions of PME with PP60 added showed a significant decrease in staining diameter, with no staining evident around the wells (no difference in staining from buffer or buffer plus PP60), indicating a loss of PME activity with PP60 addition regardless of PME concentration.

The inhibition of citrus PME by PP60 was further demonstrated by the change of the staining diameter upon addition of increasing PP60 concentrations. Variable PP60 concentration with a standard PME solution significantly affected staining diameter $\left(\mathrm{F}_{5,42}=230.1, \mathrm{p}<0.0001\right.$; Figure 1b). A Tukey's HSD post-hoc test showed significant differences among all PME+PP60 combinations and the PME control $(1 \mathrm{mg} / \mathrm{mL})$, indicating no overlap in PME activity level among these treatments. The PP60 dilution series showed a linear reduction in PME activity with PP60 concentration $\left(r^{2}=0.9281, p<0.0001\right.$; Figure 1b). Samples with PP60 added at 100 $\mathrm{mg} / \mathrm{mL}$ showed no PME activity (no ruthenium red staining). This confirms that PME activity is inhibited by PP60 and that this inhibition is concentration dependent and can be observed on agarose plates.

Our result showing PME inhibition by PP60, or green tea catechins, is consistent with previous work showing that green tea extract is a potent inhibitor of activity or expression of a variety of enzymes in vitro and in vivo (Ahmed et al., 2004; Aucamp et al., 1997; Morre et al., 2003; Okello et al., 2004; Persson et al., 2006; Vankemmelbeke et al., 2003; Zhang and Rock, 2004), including esterases (Okello et al., 2004). The enzyme-inhibiting and -inducing activities of green tea are mainly attributed to the polyphenolic flavonoids found in PP60: (-)-epicatechin (EC), (-)epigallocatechin (EGC), (-)-epicatechin gallate (ECG), (-)-epigallocatechin gallate (EGCG), and (-)-gallocatechin gallate (GCG), and while individual catechins may have differential effects, 
there may also be synergistic effects among catechins (e.g., Morre et al., 2003). These catechins can inhibit enzymes by direct competitive interactions (Persson et al., 2006; Vankemmelbeke et al., 2003), by altering regulation of expression at the genetic level (Ahmed et al., 2004), or both.

PME extracts from parasitic plants are inhibited by green tea extract.

Extracts of parasitic plant PME were combined with PP60 solution in an agarose plate experiment to determine if PP60 inhibition of PME is consistent across taxa, and specifically if catechins could inhibit PME activity in parasitic plants. PME activity in Castilleja indivisa root extracts and Cuscuta pentagona haustorial region extracts as well as the $1 \mathrm{mg} / \mathrm{mL}$ PME standard were significantly reduced by the addition of PP60 $\left(\mathrm{F}_{7,28}=1420.9, \mathrm{p}<0.0001\right.$; Figure 2). Activity was completely inhibited by PP60 addition at $50 \mathrm{mg} / \mathrm{mL}$ (stain diameter no different from buffer only or buffer plus PP60). A Tukey's HSD post-hoc test showed significantly lower PME activity in samples with PP60 added compared with PME controls (without PP60).

This experiment shows both that green tea catechin inhibition of PME is consistent and effective on various PME types, and that green tea catechins may be used to inhibit PME activity in parasitic plants. Parasitic plants utilize cell wall degrading enzymes such as PME (Bar Nun and Mayer, 1999; Ben-Hod et al., 1993; Losner-Goshen et al., 1998; Veronesi et al., 2005) to invade their hosts. Furthermore, extracts of stem peelings from hosts resistant to Cuscuta dramatically inhibited the activity of many cell wall degrading enzymes in vitro (Singh and Singh, 1997). Thus, inactivation of these enzymes in the field using small, easily applied molecules such as catechins should be investigated for potential use in influencing parasitic plant behavior.

Gallate-ester containing catechins are the strongest PME inhibitors among green tea components.

Given the consistent inhibition of PME by the combined catechins in PP60, the individual catechins of green tea were utilized to determine the most active constituents of the PP60 extract in the inhibition of citrus PME. Addition of individual catechins significantly affected PME 
activity overall $\left(\mathrm{F}_{5,42}=222.1, \mathrm{p}<0.0001\right)$, and the individual components of PP60, comprising EGCG, GCG, EC, ECG and EGC, affected PME activity differently (Figure 3), with the gallateester-containing EGCG and GCG having the most significant inhibitory effect on PME (decrease from $1.82 \mathrm{~cm}$ stain diameter to 1.51 and $1.39 \mathrm{~cm}$, respectively). The Tukey's HSD test among treatments showed that addition of EC, ECG, and EGC exhibited no differences from the PME control (Figure 3). This suggests that the polyphenolic green tea extract contains only few highly active compounds involved in this inhibition.

The dominance of EGCG and GCG in inhibition of PME is consistent with studies in other systems. The gallate-containing catechins, EGCG in particular, have been implicated in inhibition of FabG and FabI reductases (Zhang and Rock, 2004), carboxypeptidases such as angiotensin-converting enzyme (Persson et al., 2006), as well as nitric oxide synthase (Singh et al., 2002), oxidases (Aucamp et al., 1997; Morre et al., 2003) and matrix-degrading metalloproteinases, or MMPs (Ahmed et al., 2004; Demeule et al., 2000; Vankemmelbeke et al., 2003 ) in in vitro systems.

Fluorometry of PME interaction with EGCG shows reduced enzymatic activity and interaction at the substrate binding site.

Fluorometric analyses of enzymatic activity were used to test the interaction of PME with EGCG. The activity of PME with and without EGCG on an artificial synthetic substrate with a fluorescent product was used to estimate the $K_{\mathrm{i}}$ for PME interaction with EGCG. Fluorometric measurements of enzymatic degradation of cyano-acetate substrate (Shan and Hammock, 2001) showed significant reduction in purified tomato (Solanum lycopersicum L.) PME activity with the addition of EGCG (Figure 4). No background fluorescence of the cyano-acetate substrate was found in the absence of PME (data not shown), indicating the stability of this substrate in the absence of enzymatic degradation. Using this technique, the estimated $K_{\mathrm{i}}$ is $420 \mu \mathrm{M} \pm 20$ $\left(r^{2}=0.995\right)$; this is higher than the $K_{i}$ of the endogenously produced PME inhibitor protein from kiwi, which has a $\mathrm{K}_{\mathrm{i}}$ of $0.053 \mu \mathrm{M}$ at pH 7 (D'Avino et al., 2003). However, it should be noted 
that the $\mathrm{K}_{\mathrm{i}}$ value for the EGCG and PME measured by this cyano-acetate substrate will likely differ from that of PME interactions with pectin, as the cyano-acetate is a much smaller substrate than the esterified pectin network normally degraded by PME.

The Lineweaver-Burk plots of EGCG interactions with PME shows no change in y-intercept with increasing inhibitor concentration, but does show a change in slope and $\mathrm{x}$-intercept with increasing EGCG concentration, suggesting a competitive inhibition mechanism (Figure S1). These experiments were limited to a small range of substrate concentrations due to quenching problems at higher concentrations; thus, our ability to definitively analyze the type of inhibition is limited. However, given the results, competitive interaction is the most appropriate interpretation. The graph is included as supplementary data.

Consistent with the kinetic results, molecular docking analysis of EGCG and PME shows that EGCG binds in the catalytic cleft of the enzyme. Specifically, extended docking of the EGCG catechin molecule to large surface area of the methyl esterase reveals that this flexible ligand molecule prefers clustering at the enzyme's active site (PDB code:1gq8) (Figure 5). The binding energy values $(\Delta \mathrm{G})$ calculated for 100 different docking positions range from -6.37 to -3.38 $\mathrm{kcal} / \mathrm{mol}$. Interestingly, the average $\Delta \mathrm{G}$ value of $-4.47 \mathrm{kcal} / \mathrm{mol}$ corresponds to the binding affinity value $\sim 800 \mu \mathrm{M}$, which is of the same order of magnitude as the measured inhibition constant. The binding mode of EGCG is characterized by ligand-protein interaction between the catalytic residues D 136, W252 and W227 and residues Q113 and E253 located in the vicinity of the active site. More specifically, a stacking interaction with W252 is observed (see Figure S2 in Supplemental materials)

The inherent fluorescence of PME with and without EGCG was used to investigate the site of EGCG binding to PME. Inherent PME fluorescence in commercial citrus extract was reduced with increasing EGCG concentration, with a concomitant rise in emission at the peak EGCG wavelength of $390 \mathrm{nM}$ (Figure S3). This suggests that fluorescence (also called Förester) 
resonance energy transfer (FRET), between the PME tryptophans $\left(\lambda_{\mathrm{em}}=340 \mathrm{~nm}\right)$ and the EGCG $\left(\lambda_{\mathrm{ex}}=340 \mathrm{nM}\right.$ and $\left.\lambda_{\mathrm{em}}=390 \mathrm{~nm}\right)$ is taking place.

Proteinaceous PME inhibitor (PMEI) from kiwi fruit inhibits by direct contact with the relatively wide active binding site cleft of PME, thus covering the binding site access point (D'Avino et al., 2003; Di Matteo et al., 2005). The FRET behavior exhibited in our samples (Figure S3), in which emissions of fluorescence from the binding site tryptophan of PME are absorbed by EGCG and re-emitted at around $390 \mathrm{~nm}$, suggests that the aromatic system in EGCG is interacting closely with tryptophan groups located on the PME molecule. Previous work by D'Avino et al.(D'Avino et al., 2003) has suggested that most of the fluorescence observed in PME is due to the two tryptophans at the catalytic site, as the other tryptophan residues in PME are minimally exposed to solvent $(<14 \%)$. Therefore, our FRET data suggest increased shielding of the exposed tryptophans at the catalytic site as a result of interaction with EGCG, providing circumstantial evidence that EGCG is interacting directly at the catalytic site of PME.

EGCG inhibits PME from multiple plant families, suggesting utility in controlling PME in vitro and in vivo.

Using agarose plate assays, we confirmed that EGCG inhibits PME from two different plant families, Solanaceae (Solanum lycopersicum, tomato) and Rutaceae (citrus). In addition, preliminary inhibition experiments using green tea extract on parasitic plant PMEs (Castilleja indivisa and Cuscuta pentagona) indicate the feasibility of inhibiting this enzyme by a similar mechanism. Purified tomato PME $(14 \mu \mathrm{M})$ and commercially available citrus PME (approximately $5 \mu \mathrm{M}$ ) were combined in agarose plates with varying concentrations of EGCG solution or buffer. This experiment showed a concentration-dependent relationship between EGCG addition and PME activity, as reflected by staining diameter. EGCG treatments had a significant effect on PME activity for both citrus PME $\left(\mathrm{F}_{9,40}=874.36, \mathrm{p}<0.0001\right)$ and tomato $\operatorname{PME}\left(\mathrm{F}_{9,40}=2245.29, \mathrm{p}<0.0001\right)$. There was a significant negative linear relationship between concentration and stain diameter for both citrus (Diameter $=1.2-0.00077 *$ Concentration, 
$\left.\mathrm{r}^{2}=0.87\right)$ and tomato PME solutions (Diameter $=1.96-0.0011 *$ Conc., $\left.r^{2}=0.94\right)$.

Taken together, these results combined with the other experiments presented here show that green tea extract has consistent inhibitory activity against PME from widely differing plant sources (i.e., citrus, tomato, and the two parasitic plants), suggesting that its inhibitory role is related to a highly conserved region of PME structure. The inhibition of citrus and tomato PME extracts by EGCG in vitro, combined with the successful inhibition of parasitic plant PME extracts with PP60, suggest that EGCG act as a non-specific pan-inhibitor for PME. The docking analyses, in conjunction with the Lineweaver-Burk analysis and the fluorometry data showing FRET between EGCG and PME indicate direct interaction of EGCG at the catalytic binding site of PME and competitive inhibition. Such interactions may be mediated via hydrophobic interactions at the S1 pocket residing at the catalytic site as suggested by Smith et al. (2004).

\section{Conclusions}

We have found that green tea catechins can be used to inhibit pectin methyl esterase activity across plant taxa, and that the inhibitory interaction occurs at the substrate binding site of PME. As a small, readily isolated molecule, EGCG may be extremely useful as a PME inhibitor in vivo to tease apart the role of PME in modulation of cell wall adhesion, rigidity, and degradation. Epigallocatechin gallate can be exogenously applied as a direct inhibitor of PME, rather than controlling PME expression at the genetic level, allowing for the manipulation of PME activity at particular life stages and in particular plant organs, and can also be used in field settings where genetically modified organisms can be problematic. Further work is needed to determine the efficacy and feasibility of field application of EGCG or green tea extracts on various plant species. We suggest that application of exogenously applied EGCG or green tea extract may also be used to block harmful PME activity in cellular processes and may have applications for plant pathogen research and control as well as in the food industry.

\section{Experimental Procedures}


Pectin infused agarose plate method for testing enzymatic activity in combination with inhibitor.

Pectin/agarose medium plates were used to test for enzymatic activity in solutions of PME and PME combined with the hypothesized inhibitor as described by Downie et al. (Downie et al., 1998). In preparation for each experiment, two $\mathrm{mm}$ diameter wells were created in the agarose medium using a cork-borer. Each well was filled with $15 \mu \mathrm{L}$ of solution in the patterns described below. For a given experiment, stock solutions of PME (citrus PME lyophilized powder, $\sim 35 \%$ protein, 198 units/mg protein, protein molecular weight $33954 \mathrm{Da}$ (Christensen et al., 1998); Sigma Aldrich, unless otherwise noted) and/or green tea extract containing at least $60 \%$ catechins (Polyphenon 60, or PP60, Sigma-Aldrich, St. Louis, MO) or individual catechin components were used, each of which was filtered at $0.2 \mu \mathrm{m}$ unless otherwise noted. For each agarose plate well, these solutions were mixed individually in 96-well plates for transfer into the agarose plates. All plates for a given experiment received identical incubation periods (after Downie et al., 1998). The plates were then rinsed with HPLC-grade water, filled with $0.05 \%$ ruthenium red solution and incubated for 45 minutes. The plates were then drained, rinsed with HPLC grade water, and then the darker pink ruthenium red staining around each well indicating the presence of de-esterified pectin (Figure 1) was measured on the back of the plate using electronic calipers to $0.01 \mathrm{~mm}$ (Mitutoyo, Japan).

Testing whether green tea catechin extract inhibits PME in a concentration dependent manner.

The first experiment tested for effects of PME concentration on the diameter of observed staining in the plates and the effect of PP60 solution on that activity. PME solutions were created by serial dilution: $1 \mathrm{mg} / \mathrm{mL}$ of lyophilized PME powder, $0.75 \mathrm{mg} / \mathrm{mL}, 0.5 \mathrm{mg} / \mathrm{mL}, 0.25 \mathrm{mg} / \mathrm{mL}$, and $0.1 \mathrm{mg} / \mathrm{mL}$. These were diluted 1:1 with HPLC grade water, or $1: 1$ with $100 \mathrm{mg} / \mathrm{mL}$ solution of PP60 in individual cells in a 96-well plate, then transferred from each cell in to the agarose plate wells. One well of each solution was placed on each of 5 plates, plus controls (water and PP60 alone). 
The second experiment investigated the relationship between PP60 concentration and inhibition of PME activity using $1 \mathrm{mg} / \mathrm{mL}$ PME solution combined 1:1 with five treatment solutions: 100 mg/ mL PP60, $50 \mathrm{mg} / \mathrm{mL}$ PP60, $20 \mathrm{mg} / \mathrm{mL}$ PP60, $1 \mathrm{mg} / \mathrm{mL}$ PP60, and water (control/calibration). These were mixed from stock solutions in individual cells in a 96-well plate, then transferred from each cell in to an agarose plate well. Four plates were used with two replicates of each solution per plate.

Preparation of parasitic plant PME extracts.

The third experiment tested the effect of PP60 on extracts of PME from Castilleja indivisa, a root hemiparasite and from Cuscuta pentagona, a stem holoparasite. Cuscuta pentagona cuttings grown on Vicia faba were placed in water tubes and exposed to Coleus spp. stem for 4 days, then harvested and extracted. Castilleja indivisa were harvested from soil and roots were rinsed in HPLC-grade water. For the two species, $95.8 \mathrm{mg}$ Cuscuta pentagona cuttings and approximately $165 \mathrm{mg}$ of freshly harvested and rinsed Castilleja indivisa root material were placed into $400 \mu \mathrm{L}$ and $600 \mathrm{uL}$ respectively of $0.1 \mathrm{M}$ citrate/ $0.2 \mathrm{M}$ phosphate buffer at $\mathrm{pH} 7$ with $3 \mathrm{~g}$ of $2.3 \mathrm{~mm}$ chrome steel beads. The tissue was ground for 10 seconds on high in a Beadbeater (Biospec products), then allowed to incubate for approximately three hours at room temperature (after Downie et al., 1998). A portion of the resulting slurry was diluted approximately 1:1 with buffer and used without filtration. The following solutions were mixed individually in cells in 96-well plates and then transferred to individual wells in the three agarose plates: $C$. indivisa PME extract + buffer (2/plate), C. indivisa PME extract + PP60 (50 mg/ mL) (2/plate), C. pentagona PME extract + buffer (2/plate), C. pentagona PME extract + PP60 (50 mg/ mL) (2/plate), PME $1.0 \mathrm{mg} / \mathrm{mL}+$ buffer (1/plate), PME $1.0 \mathrm{mg} / \mathrm{mL}+$ PP60 (1/plate), buffer control (1/plate), and PP60 + buffer (1/plate).

\section{Test for inhibitory effects of individual catechins.}

The fourth experiment tested individual polyphenolic flavonoid components of PP60 (individual catechins purchased from Sigma Aldrich, St. Louis, MO) for differential inhibition of 
commercially available PME. PME solution was made up to $1 \mathrm{mg} / \mathrm{mL}$ in $0.1 \mathrm{M}$ citrate/0.2 M phosphate buffer at $\mathrm{pH}$ 7. This solution was filtered (0.4 um PTFE filter, Acrodisc), then diluted to $0.75 \mathrm{mg} / \mathrm{mL}$. All PP60 components were diluted in buffer to $20 \mathrm{mg} / \mathrm{mL}$, then filtered $(0.4$ $\mu \mathrm{m}$ PTFE filter, Acrodisc) to remove particulate while maximizing activity in solution. Maximum concentration of each solution was EC: 34.45 mM, EGC: 32.65 mM, ECG: 22.61 mM, GCG: $21.82 \mathrm{mM}$, EGCG: $21.82 \mathrm{mM}$. The following solutions (four plates, 2/plate) were mixed individually in a 96-well tray prior to placement in agarose plate wells: PME + buffer, $\mathrm{PME}+\mathrm{EGC}, \mathrm{PME}+\mathrm{ECG}, \mathrm{PME}+\mathrm{EGCG}, \mathrm{PME}+\mathrm{GCG}, \mathrm{PME}+\mathrm{EC}$.

Fluorometry of PME Interaction with EGCG.

To closely monitor PME interaction with EGCG using fluorometric kinetic analysis, tomato PME was purified as previously described (Vovk and Simonovska, 2007). The enzymatic activity of purified tomato PME and inhibition by EGCG were measured at $37^{\circ} \mathrm{C}$ by monitoring the hydrolysis of a cyano-acetate as a substrate (provided by Guomin Shan and Bruce D. Hammock, University of California, Davis) at $\lambda_{\mathrm{ex}}=340 \mathrm{~nm}$ and $\lambda_{\mathrm{em}}=465 \mathrm{~nm}$ as described by (Shan and Hammock, 2001). The standard assay mixture contained $20 \mathrm{mM}$ Tris, pH 7.0 and 100 $\mathrm{mM} \mathrm{NaCl}$.

The steady-state kinetic data were processed and analyzed by linear and non-linear regression using Kaleidagraph 3.5. The initial velocities were calculated by using a linear fit followed by non-linear fit to the Michaelis-Menten equation as shown in Equation 1.

$V_{i}=V_{\max } S /\left(K_{m}+S\right)$

where $V_{i}$ is the initial velocity, $V_{\max }$ is the maximum velocity, $S$ is the substrate concentration, and $K_{m}$ is the Michaelis-Menten constant.

The inhibition constant measurement was determined by pre-incubating PME $(2 \mu \mathrm{M})$ with increasing concentrations of EGCG ranging from 0 to $4.0 \mathrm{mM}$. Incubation was allowed at $37{ }^{\circ} \mathrm{C}$ for 30 min before steady state measurement. The cyano-acetate substrate was added to a final 
concentration of $10 \mu \mathrm{M}$ to initiate the assays. Measurements of PME activities were performed at $37^{\circ} \mathrm{C}$. The $K_{i}$ values were calculated using Equation 2.

$V_{i}=V_{\max } S /\left(K_{m}\left(1+I / K_{i}\right)+S\right) \quad$ Eq. 2

The kinetic data measured in different substrate concentrations were subjected to LineweaverBurk analysis. When used for determining the type of enzyme inhibition, the Lineweaver-Burk plot can distinguish competitive, noncompetitive and uncompetitive inhibitors. In this case, the $\mathrm{V}_{\max }$ (maximum speed of the reaction) is unchanged (same y-intercept), while $\mathrm{K}_{\mathrm{m}}$ (the apparent affinity of the substrate to the binding site) is decreased (different $x$-intercept).

To test whether the interaction of EGCG with PME occurs at the substrate binding site, the inherent fluorescence of PME, and PME fluorescence with incremental additions of EGCG were measured. In the unbound state, the binding site of the PME molecule has two exposed tryptophan residues that absorbs light at $295 \mathrm{~nm}$ and emits light at approximately $340 \mathrm{~nm}$ (D'Avino et al., 2003), whereas the other tryptophans in plant PMEs appear to be deep within the folded structure of the protein and not accessible to the solvent; these therefore should not contribute to the observed quenching resulting from interaction with inhibitors (D'Avino et al., 2003). The EGCG molecule absorbs light at $340 \mathrm{~nm}$ and emits radiation at $390 \mathrm{~nm}$. Thus, if the EGCG is bound very close to the tryptophan residue of PME, fluorescence resonance energy transfer (FRET) can occur, in which EGCG absorbs the tryptophan fluorescence. If this occurs, a shift should be observed in the peak emission spectrum of the complex from $340 \mathrm{~nm}$ to $390 \mathrm{~nm}$ upon addition of EGCG, and the emission at 390 should increase as the emission at 340 decreases.

For the FRET experiment, a solution of $0.5 \mathrm{mg} / \mathrm{mL}$ of lyophilized citrus PME powder (SigmaAldrich, St. Louis, MO) was dissolved in $0.1 \mathrm{M}$ citrate/0.2 $\mathrm{M}$ phosphate buffer at $\mathrm{pH} 7$ (approximately $10.3 \mu \mathrm{M}$ ). A serial dilution of EGCG was prepared ranging from 1.0 to 10.0 $\mathrm{mM}$. Fluorescence was measured in a quartz cuvette (Spectrosil quartz, Starna Cells, Inc., Atascadero, CA) on a Jasco J-810 Spectropolarimeter (Jasco, Easton, MD) at $\lambda_{\mathrm{ex}}=295 \mathrm{~nm}$, and 
$\lambda_{\mathrm{em}}=320$ to $450 \mathrm{~nm}$. After measuring a baseline scan of the PME solution to confirm peak PME $\lambda_{\mathrm{em}}=340 \mathrm{~nm}$ (D'Avino et al., 2003), sequential $2 \mu \mathrm{L}$ aliquots of concentrated EGCG solution (increasing concentration by $20.0 \mathrm{nM}$ per aliquot) were added to the cuvette and mixed gently, then incubated in the dark for 2 minutes prior to scanning. Additions were performed until changes in PME fluorescence leveled off. Background fluorescence of the buffer was subtracted from all spectra.

\section{Molecular docking analysis}

To explore possible interactions of EGCG molecule in the PME active site, we employed the AutoDock protocol, which has been shown to reproduce ligand-protein binding modes efficiently (Morris et al., 1998). The docking algorithm used in this study treats ligands as flexible molecules, while keeping protein conformation restrained (PDB code:1gq8). All 12 non-cyclic $\sigma$ bond torsions of the EGCG molecule were free to rotate. Partial charges on the ligand atoms were calculated by semi-empirical AM1 method (MOPAC7 program). Gasteiger partial charges were applied to enzyme molecule. A cubic grid $50 \AA \times 50 \AA \times 50 \AA$ around the active site was built by the autogrid program. Grid point step $0.375 \AA$ was taken. A Lamarckian genetic algorithm coupled with local search was used for docking with the default values as implemented in AutoDock4. The number of docking runs was set to 100. To generate input files, AutoDockTools (ADT) program (http://www.scripps.edu/pub/olsonweb/doc/autodock/tools.html) was used.

\section{Comparison of tomato and citrus PME inhibition by EGCG.}

The pectin degradation activity of two different types of PME were tested in combination with varying concentrations of EGCG. Commercially available citrus PME (Sigma Aldrich, St. Louis, MO) was made up to $0.5 \mathrm{mg} / \mathrm{mL}$ in $0.1 \mathrm{M}$ citrate/ $0.2 \mathrm{M}$ phosphate buffer at $\mathrm{pH} 7$, then filtered (0.2 $\mu \mathrm{m}$ PTFE filter, Acrodisc) to remove any remaining particulate. Tomato PME was extracted and purified as previously described (Vovk and Simonovska, 2007). EGCG powder (Sigma Aldrich, St. Louis, MO) was dissolved in the buffer to a concentration of $40 \mathrm{mM}$ by 
warming the tube very slightly under running tap water, then serially diluted to $30,20,10,5,2.5$, and $1 \mathrm{mM}$. Five plates were used for each PME source, each plate containing one well with buffer, one with EGCG alone, one with the PME solution and buffer, and one each of the PME solution plus each of the EGCG solutions. All solutions for each well were mixed individually in 96-well trays prior to placement in the agarose plate wells.

\section{Statistical analyses.}

Data were analyzed using JMP Statistical Software (V. 5.0.1.2, SAS Institute). A standard least squares fit model was used to test two models; one in which treatment was nested within plate (where there was replication within plates) and, if plate did not contribute significantly to variance, one in which only treatment was tested for effects on staining diameter. In the one case in which a plate effect was found (in the individual catechin experiment) the effect of treatment was tested both by excluding the outlying plate and by averaging the diameter of the treatments within plate and performing the one-way ANOVA for effects of treatment on stain diameter. No qualitative differences in results were detected. Plate level averages are presented. Tukey's HSD post-hoc tests were used to compare among treatments.

\section{Acknowledgments}

We thank Guomin Shan and Bruce D. Hammock, University of California, Davis, for supplying the fluorescent cyano-acetate substrate, Peer Fischer of Rowland Institute at Harvard for fluorometry advice and equipment, Janice Alers-García, Rachel Spicer and Leslie Wright, Rowland Institute at Harvard, for helpful discussion, Jason Figueiredo, Rowland Institute at Harvard for graphics assistance, and Anna Elushin, Weizmann Institute, for technical support. We thank four anonymous reviewers for helpful comments on the manuscript. This work was supported by a Junior Fellowship to K.C.L. from the Rowland Institute at Harvard. I.S. is supported by the Israel Science foundation, the Kimmelman Center at the Weizmann Institute, and the Ambach family fund. I.S. is the incumbent of the Pontecorvo professorial chair. 


\section{References}

Ahmed, S., Wang, N. Z., Lalonde, M., Goldberg, V. M., Haqqi, T. M., 2004. Green tea polyphenol epigallocatechin-3-gallate (EGCG) differentially inhibits interleukin-1 beta-induced expression of matrix metalloproteinase-1 and-13 in human chondrocytes. J. Pharmacol. Exp. Ther. 308, 767-773.

Aucamp, J., Gaspar, A., Hara, Y., Apostolides, Z., 1997. Inhibition of xanthine oxidase by catechins from tea (Camellia sinensis). Anticancer Res. 17, 4381-4385.

Bar Nun, N., Mayer, A. M., 1999. Culture of pectin methylesterase and polyphenoloxidase in Cuscuta campestris. Phytochemistry 50, 719-727.

Ben-Hod, G., Losner, D., Joel, D. M., Mayer, A. M., 1993. Pectin Methylesterase In Calli And Germinating Seeds Of Orobanche aegyptiaca. Phytochemistry 32, 1399-1402.

Brummell, D. A., 2006. Cell wall disassembly in ripening fruit. Functional Plant Biology 33, 103-119.

Christensen, T., Nielsen, J. E., Kreiberg, J. D., Rasmussen, P., Mikkelsen, J. D., 1998. Pectin methyl esterase from orange fruit: characterization and localization by in-situ hybridization and immunohistochemistry. Planta 206, 493-503.

D'Avino, R., Camardella, L., Christensen, T., Giovane, A., Servillo, L., 2003. Tomato pectin methylesterase: Modeling, fluorescence, and inhibitor interaction studies-comparison with the bacterial (Erwinia chrysanthemi) enzyme. Proteins: Struct., Funct., Genet. 53, 830-839.

Demeule, M., Brossard, M., Page, M., Gingras, D., Beliveau, R., 2000. Matrix metalloproteinase inhibition by green tea catechins. Biochim. Biophys. Acta: Prot. Struct. Funct. 1478, 51-60. Derbyshire, P., McCann, M. C., Roberts, K., 2007. Restricted cell elongation in Arabidopsis hypocotyls is associated with a reduced average pectin esterification level. BMC Plant Biology 7.

Di Matteo, A., Giovane, A., Raiola, A., Camardella, L., Bonivento, D., De Lorenzo, G., Cervone, F., Bellincampi, D., Tsernoglou, D., 2005. Structural basis for the interaction between pectin methylesterase and a specific inhibitor protein. Plant Cell 17, 849-858.

Downie, B., Dirk, L. M. A., Hadfield, K. A., Wilkins, T. A., Bennett, A. B., Bradford, K. J., 1998. A gel diffusion assay for quantification of pectin methylesterase activity. Anal. Biochem. 264, 149-157.

Giovane, A., Servillo, L., Balestrieri, C., Raiola, A., D'Avino, R., Tamburrini, M., Clardiello, M. A., Camardella, L., 2004. Pectin methylesterase inhibitor. Biochimica Et Biophysica Acta: Proteins And Proteomics 1696, 245-252.

Holmquist, B., Vallee, B. L., 1976. Esterase-Activity Of Zinc Neutral Proteases. Biochemistry 15, 101-107. 
Jarvis, M. C., Briggs, S. P. H., Knox, J. P., 2003. Intercellular adhesion and cell separation in plants. Plant, Cell Environ. 26, 977-989.

Jiang, L. X., Yang, S. L., Xie, L. F., Puah, C. S., Zhang, X. Q., Yang, W. C., Sundaresan, V., Ye, D., 2005. VANGUARD1 encodes a pectin methylesterase that enhances pollen tube growth in the Arabidopsis style and transmitting tract. Plant Cell 17, 584-596.

Juge, N., 2006. Plant protein inhibitors of cell wall degrading enzymes. Trends In Plant Science 11, 359-367.

Koch, J. L., Nevins, D. J., 1989. Tomato Fruit Cell-Wall.1. Use Of Purified Tomato

Polygalacturonase And Pectinmethylesterase To Identify Developmental-Changes In Pectins. Plant Physiol. 91, 816-822.

Li, Y. Q., Chen, F., Linskens, H. F., Cresti, M., 1994. Distribution Of Unesterified And Esterified Pectins In Cell-Walls Of Pollen Tubes Of Flowering Plants. Sexual Plant Reproduction 7, 145-152.

Losner-Goshen, D., Portnoy, V. H., Mayer, A. M., Joel, D. M., 1998. Pectolytic activity by the haustorium of the parasitic plant Orobanche L. (Orobanchaceae) in host roots. Annals Of Botany 81, 319-326.

Micheli, F., Holliger, C., Goldberg, R., Richard, L., 1998. Characterization of the pectin methylesterase-like gene AtPME3: a new member of a gene family comprising at least 12 genes in Arabidopsis thaliana. Gene 220, 13-20.

Micheli, F., Sundberg, B., Goldberg, R., Richard, L., 2000. Radial distribution pattern of pectin methylesterases across the cambial region of hybrid aspen at activity and dormancy. Plant Physiol. 124, 191-199.

Morre, D. J., Morre, D. M., Sun, H., Cooper, R., Chang, J., Janle, E. M., 2003. Tea catechin synergies in inhibition of cancer cell, proliferation and of a cancer specific cell surface oxidase (ECTO-NOX). Pharmacol. Toxicol. (Copenhagen) 92, 234-241.

Morris, G. M., Goodsell, D. S., Halliday, R. S., Huey, R., Hart, W. E., Belew, R. K., Olson, A. J., 1998. Automated docking using a Lamarckian genetic algorithm and an empirical binding free energy function. J. Comput. Chem. 19, 1639-1662.

Nagar, R., Singh, M., Sanwal, G. G., 1984. Cell-Wall Degrading Enzymes In Cuscuta reflexa And Its Hosts. J. Exp. Bot. 35, 1104-1112.

Nielsen, J. E., Christensen, T., 2002. Distribution of pectin methyl esterase and acetylesterase in the genus Citrus visualized by tissue prints and chromatography. Plant Science 162, 799-807.

Okello, E. J., Saverev, S. U., Perry, E. X., 2004. In vitro anti-beta-secretase and dual anticholinesterase activity of Camellia sinensis L. (tea) relevant to treatment of dementia. Phytotherapy Research 18, 624-627.

Persson, I. A. L., Josefsson, M., Persson, K., Andersson, R. G. G., 2006. Tea flavanols inhibit angiotensin-converting enzyme activity and increase nitric oxide production in human endothelial cells. J. Pharm. Pharmacol. 58, 1139-1144.

Pilling, J., Willmitzer, L., Bucking, H., Fisahn, J., 2004. Inhibition of a ubiquitously expressed pectin methyl esterase in Solanum tuberosum L. affects plant growth, leaf growth polarity, and ion partitioning. Planta 219, 32-40. 
Raiola, A., Camardella, L., Giovane, A., Mattei, B., De Lorenzo, G., Cervone, F., Bellincampi, D., 2004. Two Arabidopsis thaliana genes encode functional pectin methylesterase inhibitors. FEBS Lett. 557, 199-203.

Shan, G. M., Hammock, B. D., 2001. Development of sensitive esterase assays based on alphacyano-containing esters. Anal. Biochem. 299, 54-62.

Singh, A., Singh, M., 1997. Incompatibility of Cuscuta Haustoria with the resistant hosts Ipomoea batatas L and Lycopersicon esculentum Mill. J. Plant Physiol. 150, 592-596.

Singh, R., Ahmed, S., Islam, N., Goldberg, V. M., Haqqi, T. M., 2002. Epigallocatechin-3gallate inhibits interleukin-1 beta-induced expression of nitric oxide synthase and production of nitric oxide in human chondrocytes - Suppression of nuclear factor kappa B activation by degradation of the inhibitor of nuclear factor kappa B. Arthritis And Rheumatism 46, 2079-2086. Smith, D. M., Daniel, K. G., Wang, Z. G., Guida, W. C., Chan, T. H., Dou, Q. P., 2004. Docking studies and model development of tea polyphenol proteasome inhibitors: Applications to rational drug design. Proteins: Struct., Funct., Genet. 54, 58-70.

Vankemmelbeke, M. N., Jones, G. C., Fowles, C., Ilic, M. Z., Handley, C. J., Day, A. J., Knight, C. G., Mort, J. S., Buttle, D. J., 2003. Selective inhibition of ADAMTS-1,-4 and -5 by catechin gallate esters. Eur. J. Biochem. 270, 2394-2403.

Vaughn, K. C., 2003. Dodder hyphae invade the host: a structural and immunocytochemical characterization. Protoplasma 220, 189-200.

Veronesi, C., Bonnin, E. F., Benharrat, H., Fer, A., Thalouarn, P., 2005. Are pectinolytic activities of Orobanche cumana seedlings related to virulence towards sunflower? Israel Journal Of Plant Sciences 53, 19-27.

Vovk, I., Simonovska, B., 2007. Isolation of tomato pectin methylesterase and polygalacturonase on monolithic columns. Journal Of Chromatography A 1144, 90-96.

Willats, W. G. T., Orfila, C., Limberg, G., Buchholt, H. C., van Alebeek, G., Voragen, A. G. J., Marcus, S. E., Christensen, T., Mikkelsen, J. D., Murray, B. S., Knox, J. P., 2001. Modulation of the degree and pattern of methyl-esterification of pectic homogalacturonan in plant cell walls Implications for pectin methyl esterase action, matrix properties, and cell adhesion. J. Biol. Chem. 276, 19404-19413.

Wolf, S., Grsic-Rausch, S., Rausch, T., Greiner, S., 2003. Identification of pollen-expressed pectin methylesterase inhibitors in Arabidopsis. FEBS Lett. 555, 551-555.

Zhang, G. F., Staehelin, L. A., 1992. Functional Compartmentation Of The Golgi-Apparatus Of Plant-Cells - Immunocytochemical Analysis Of High-Pressure Frozen-Substituted And FreezeSubstituted Sycamore Maple Suspension-Culture Cells. Plant Physiol. 99, 1070-1083. Zhang, Y. M., Rock, C. O., 2004. Evaluation of epigallocatechin gallate and related plant polyphenols as inhibitors of the FabG and FabI reductases of bacterial type II fatty-acid synthase. J. Biol. Chem. 279, 30994-31001. 
Figure 1: Varying PME activity and varying PP60 concentration affect stain diameter on agarose plates. A) Relationship of diameter of staining and citrus PME concentration; B) relationship of diameter of staining of a consistent citrus PME solution with the addition of varied PP60 concentration, with 95\% confidence limits.

Figure 1
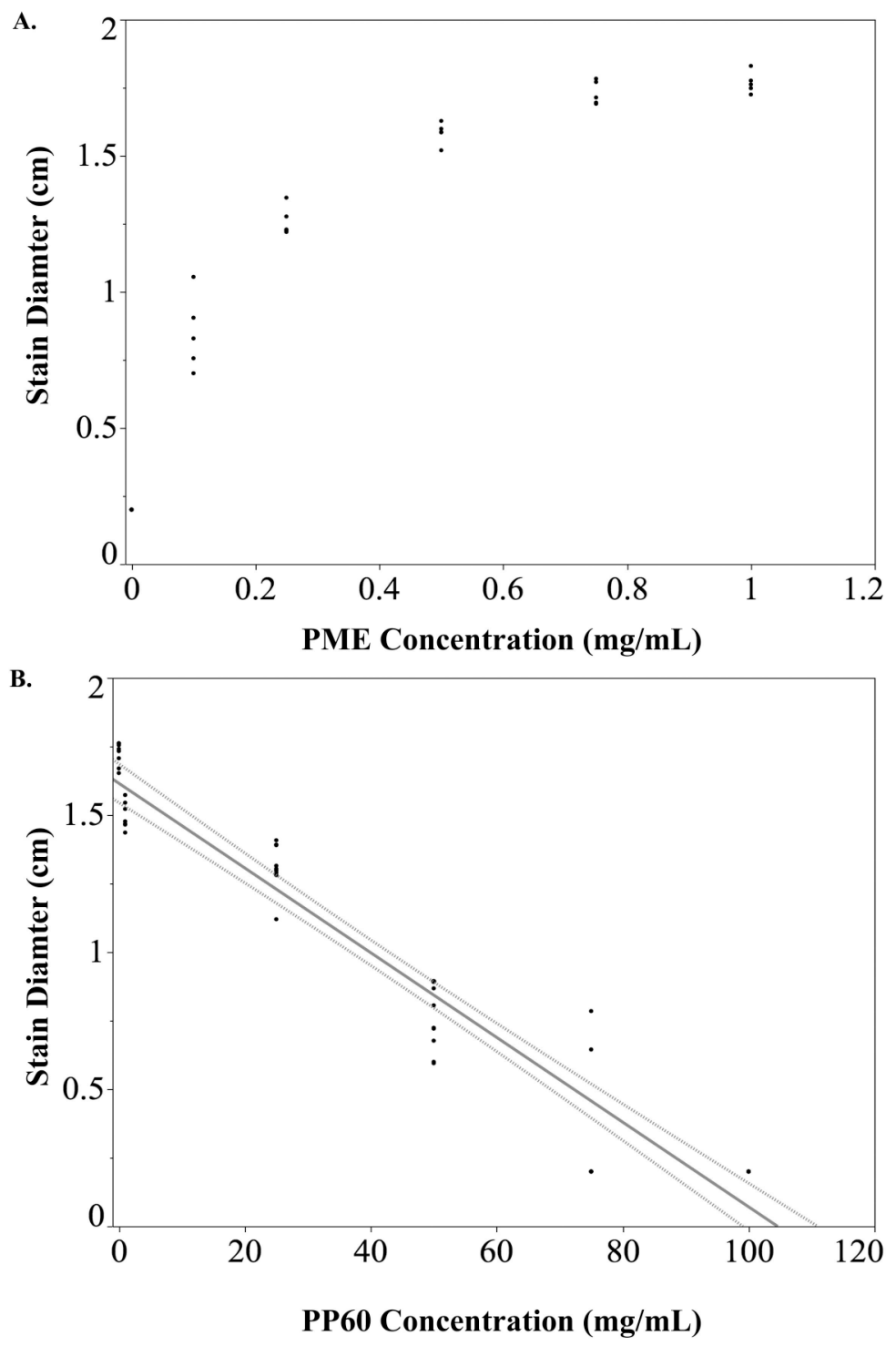
Figure 2: Parasitic plant PME extracts inhibited by PP60. Mean diameter of staining showing one-way ANOVA results (effect of treatment $\mathrm{F}_{7,28}=1470.9, \mathrm{p}<0.0001$ ) and Tukey's HSD test results for citrus PME solution $(1 \mathrm{mg} / \mathrm{mL})$, C. pentagona and C. indivisa PME extract with PP60 (50 mg/ mL) added. Diamonds are 95\% confidence intervals. Non-overlapping circles in the Tukey's HSD test show significant differences.

\section{Figure 2}

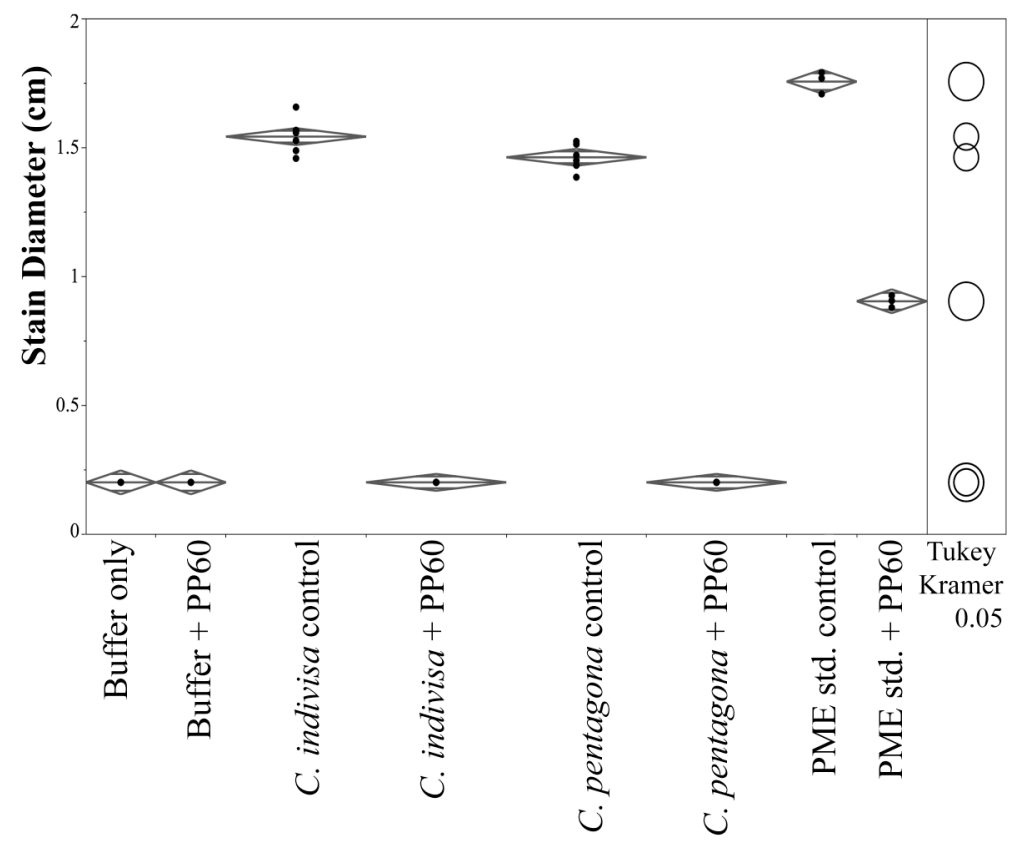


Figure 3: Individual catechin effects on PME. Mean diameter of staining showing one-way ANOVA results (treatment main effect, $\mathrm{F}_{5,18}=162.4, \mathrm{p}<0.0001$ ) and Tukey's HSD test results for citrus PME solution $(0.75 \mathrm{mg} / \mathrm{mL})$ with PP60 components added. Diamonds are 95\% confidence intervals. Non-overlapping circles in the Tukey's HSD test show significant differences.

Figure 3

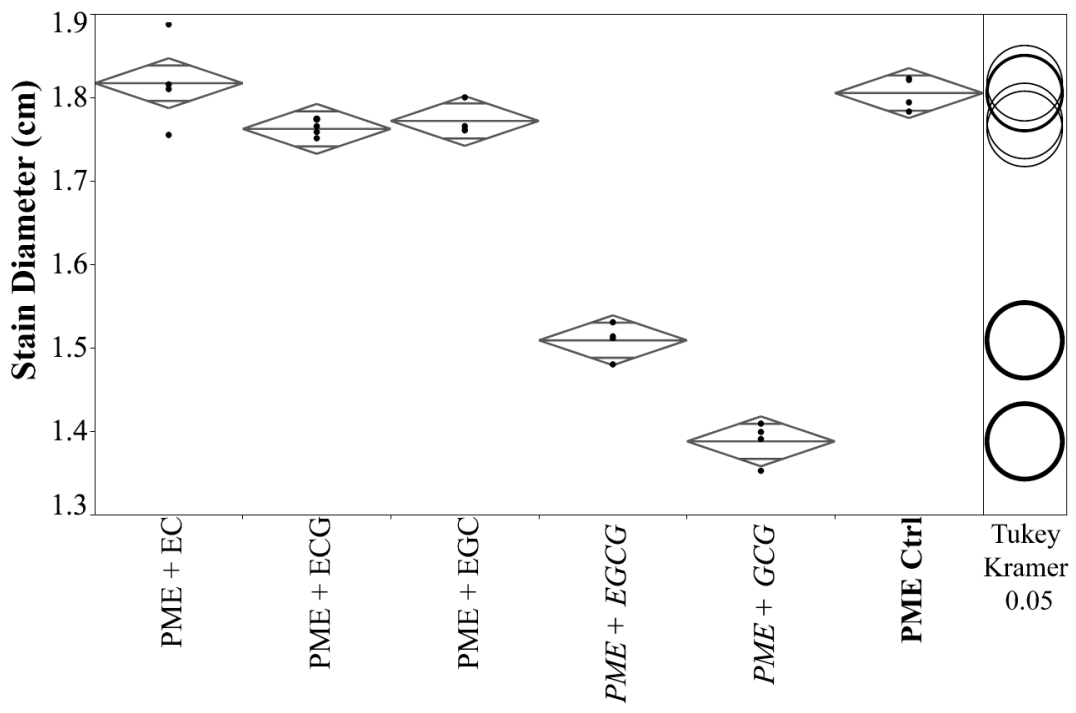


Figure 4: Fluorometry shows PME inhibition by EGCG. Comparison of baseline PME esterase activity (top line, in black) with the inhibition of purified tomato PME activity by EGCG (0-4.0 mM). The series of lines show decreasing production of the cyano-acetate fluorescent product $\left(\lambda_{\mathrm{em}}=465 \mathrm{~nm}\right)$ in PME solutions with increasing concentration of EGCG. The inset shows the relationship between inhibitor concentration and the ratio of fluorescence of the solution versus the baseline. $K_{\mathrm{i}}=420 \mu \mathrm{M} \pm 20$ (curve fit $\mathrm{r}^{2}=0.995$ );

Figure 4

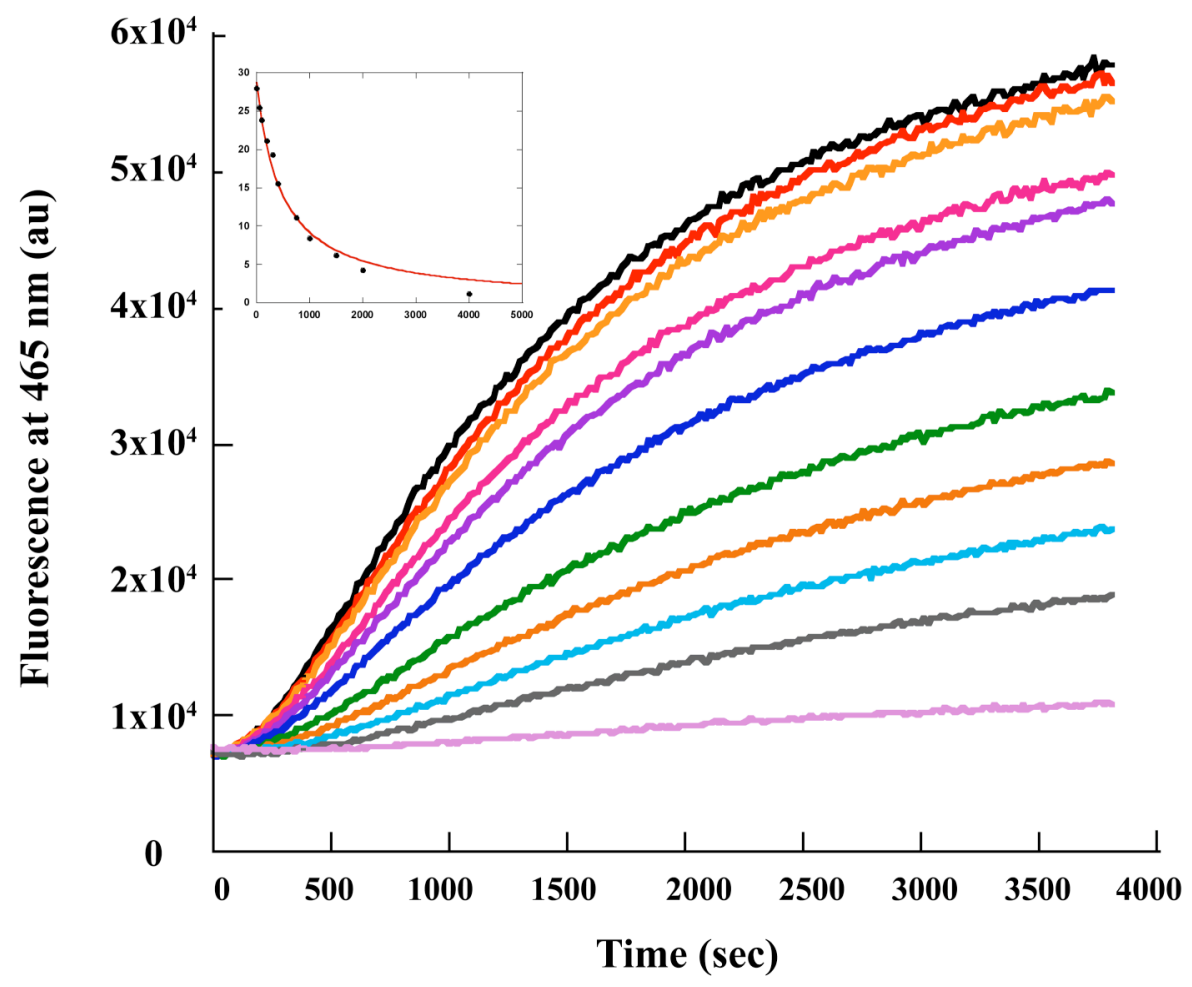


Figure 5: Docking model results showing the interaction of EGCG with the catalytic site of PME. Green spheres represent distribution of the ligand's geometric centres around the binding site area. The number of spheres (100) corresponds to the number of the random docking runs. Catalytic residues D136, D157, W252 and W227 are highlighted (PDB code:1gq8).

\section{Figure 5}

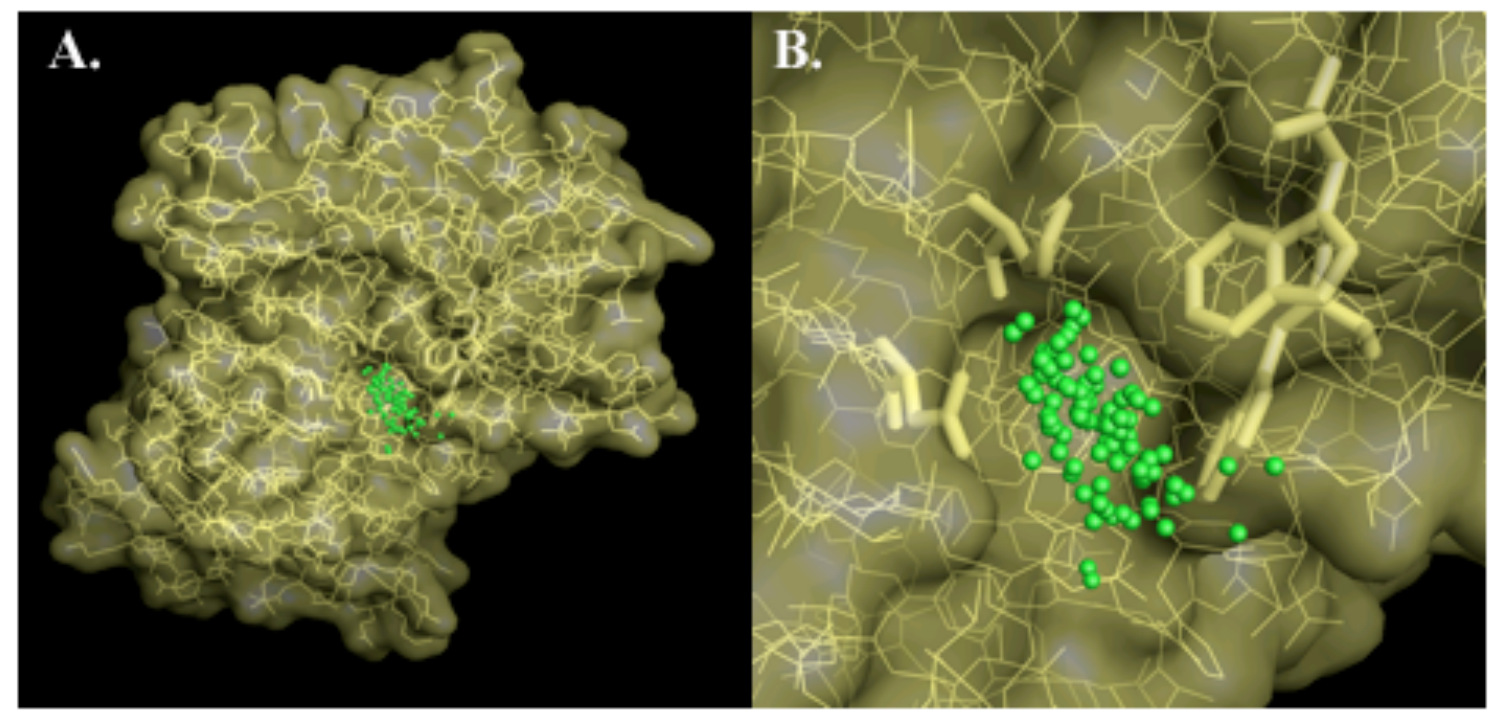




\section{Supplementary Data for Online Publication}

Figure S1: Lineweaver-Burk Plot for interaction of purified tomato PME with EGCG, indicating competitive interaction. This analysis was limited to a small range of substrate concentrations due to quenching problems at higher concentrations.

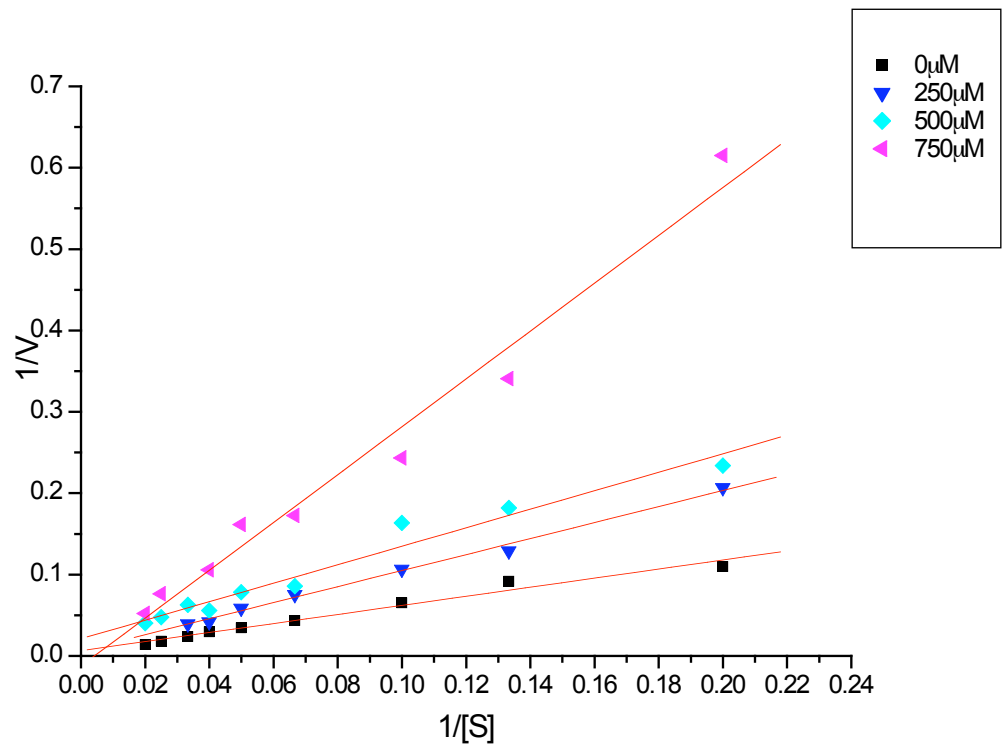


Figure S2: Closeup of interaction of EGCG with PME binding site. The most populated conformations (colored by orange and blue) are also top-ranked among other clusters by the binding energy scoring. These two binding modes differ in orientation of the ester carbonyl group and 3,4,5-three-hydroxybenzene ring. (PDB code:1gq8)

$1^{\text {st }}$ Binding Mode is characterized by ligand-protein interaction (Figure S2) as described below:

Stacking interaction with W252

Hydrogen bond to W252 backbone oxygen

2 hydrogen bonds to E253

1 hydrogen bond to Q113

1 hydrogen bond to Q135

2 hydrogen bonds to D136

2 hydrogen bonds from R235 to ligand

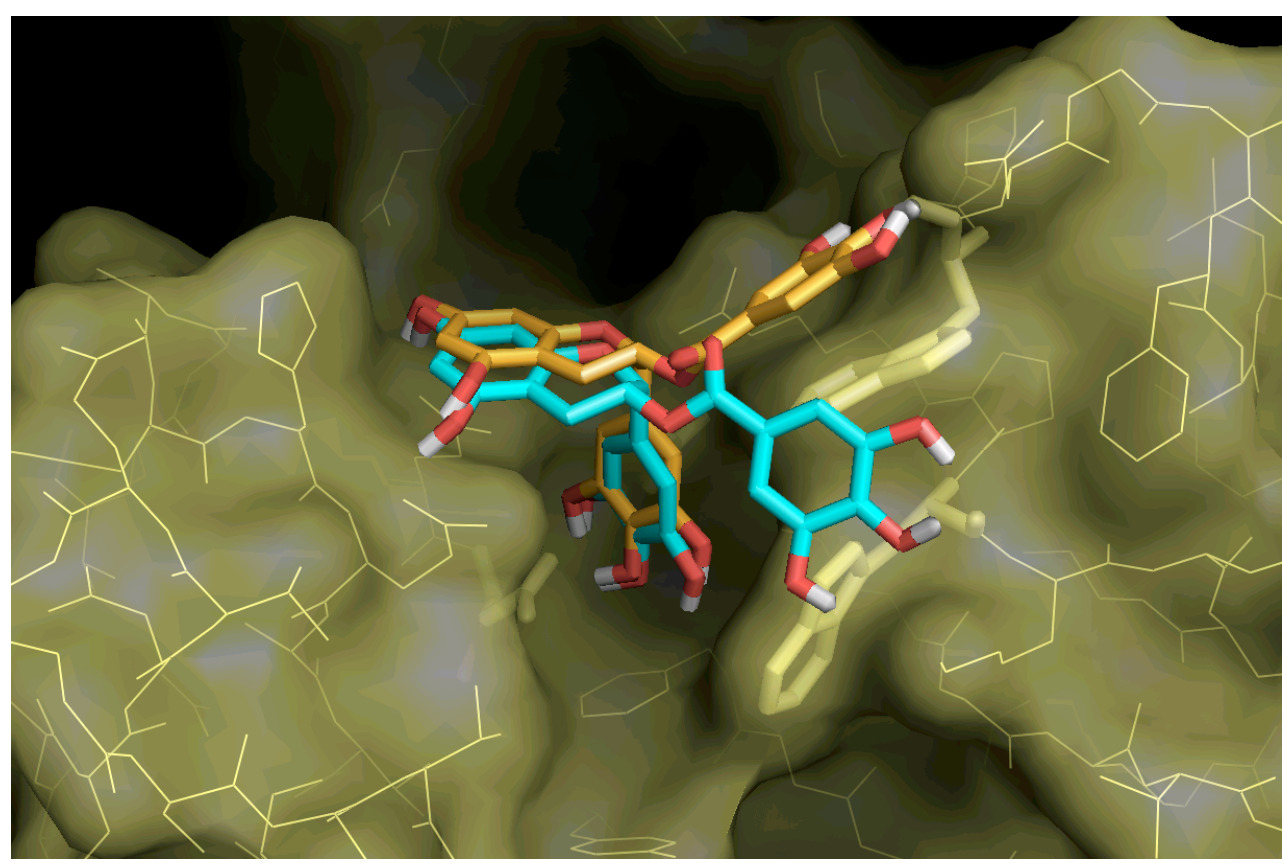


Figure S3: Fluorometric data showing fluorescence resonance energy transfer (FRET)

between PME and EGCG. A) Effects of sequential EGCG addition to citrus PME solution on inherent fluorescence intensity, showing decreased fluorescence by the PME (peak at approximately $340 \mathrm{~nm}$ ), and concomitant FRET signal showing an increase in EGCG fluorescence emission at approximately $390 \mathrm{~nm}$ due very close proximity to the PME tryptophans;

B) Active site cleft of PME (PDB code:1gq8) defined by residues D136, D157, colored in red; W227 and W252 colored in yellow are located at the rim of the active site;

C) The structure of EGCG.

\section{Figure S3}

A.

$\quad 0.7$

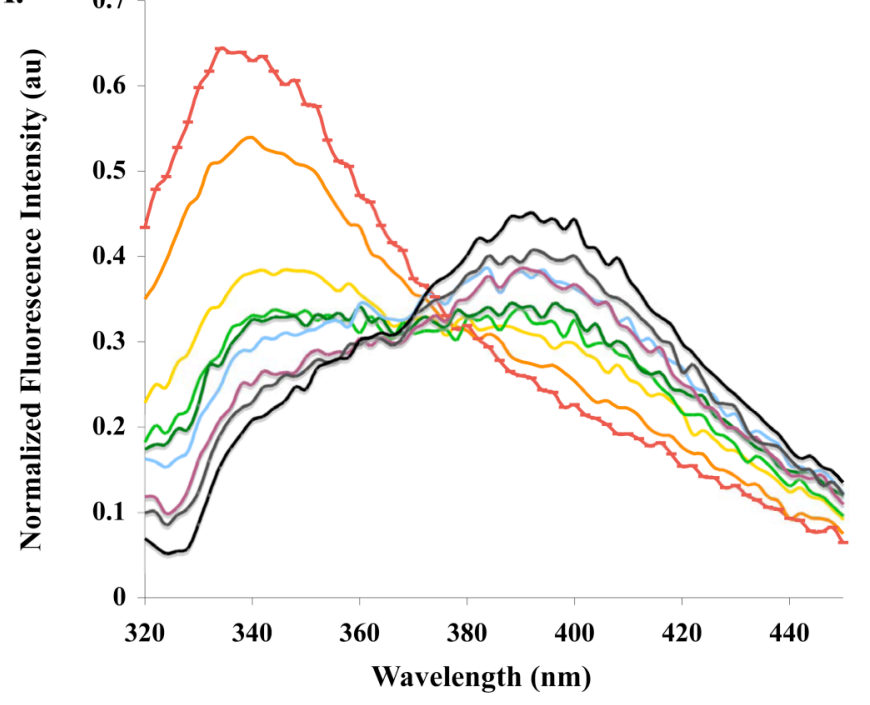

- $2.5 \mathrm{uM} \mathrm{PME}$

PME+20 uM EGCG - PME+40 uM EGCG

- $\mathrm{PME}+60 \mathrm{uM}$ EGCG

- $\mathrm{PME}+80$ uM EGCG

- PME+100 uM EGCG

- PME+120 uM EGCG

- $\mathrm{PME}+140$ uM EGCG

- $\mathrm{PME}+180 \mathrm{uM}$ EGCG

B.
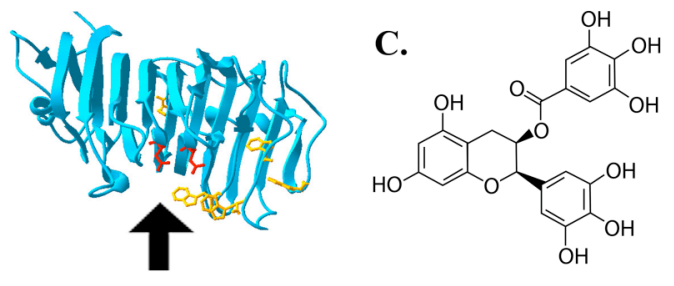